\title{
STUDY OF THE EFFECT OF INJECTION CURRENTS ON WHITE LIGHT EMISSION OF Ce-DOPED YAG PHOSPHOR POWDER PREPARED BY MICROWAVE COMBUSTION
}

\author{
Husnen R. Abd ${ }^{1, *}$, Z. Hassan, ${ }^{2, *}$, Naser M. Ahmed ${ }^{1}$ \\ ${ }^{1}$ School of Physics, Universiti Sains Malaysia, 11800 USM, Penang, MALAYSIA. \\ (E-mail: husnen1978@gmail.com) \\ ${ }^{2}$ Institute of Nano Optoelectronics Research and Technology (INOR), Universiti Sains \\ Malaysia, 11800 USM, Penang, MALAYSIA. \\ (E-mail:zai@usm.my)
}

\begin{abstract}
Cerium doped yttrium aluminum garnet (YAG:Ce ${ }^{+3}$ ) nanopowders have been synthesized using microwave combustion (MW) according to the formula, $\mathrm{Y}_{(3-}$ ${ }_{0.04)} \mathrm{Al}_{5} \mathrm{O}_{12}: 0.04 \mathrm{Ce}^{+3}$ to produce white light emitting diode (WLED) by conversion from blue indium gallium nitride light emitting diode (InGaN LED, $445 \mathrm{~nm}$ ) chips; the whole process took only $20 \mathrm{~min}$. Pure YAG phase was obtained at sintering temperature of $1050^{\circ} \mathrm{C}$ for $5 \mathrm{~h}$ with nonaggregated and spherical particles. Thermogravimetry and derivative thermogravimetry (TG/DTG), X-ray powder diffraction (XRPD), transmission electron microscope (TEM), electroluminescence (EL) emissions and standard CIE 1931 chromaticity diagrams have been used to characterize the samples. The highest WLED emission was achieved for the annealed YAG:Ce, together with proper color rendering index (CRI), and tunable correlated color temperature (CCT). Finally, we conclude that the decreasing EL intensity at increased injection current is caused by the thermal ionization from the $5 \mathrm{~d}_{1}$ level to the conduction band.
\end{abstract}

Keywords: white LED, YAG: $\mathrm{Ce}^{+3}$, microwave combustion technique, CRI, thermal ionization. 